\title{
The 'stay-at-home' mother, postfeminism and neoliberalism: Content analysis of UK news coverage
}

European Journal of Communication 2015, Vol. 30(4) 4I8-436

(C) The Author(s) 2015

Reprints and permissions: sagepub.co.uk/journalsPermissions.nav DOI: I0.1 I77/0267323 I I5586724 ejc.sagepub.com

(S)AGE

\section{Shani Orgad}

London School of Economics and Political Science, UK

\section{Sara De Benedictis}

King's College London, UK

\begin{abstract}
This article analyzes the construction in the UK media of the 'stay-at-home mother', a maternal figure who received increasing visibility during the recession and its aftermath. Based on a content analysis of UK national newspaper coverage of stay-at-home mothers (2008-2013), this article argues that the stay-at-home mother emerges from its press coverage as a neoliberal postfeminist subject. On the one hand, the coverage complicates claims about antifeminist backlash and women's harking back to passive femininity. On the other hand, it fails significantly to undermine maternal femininity's entanglement with neoliberalism, and reinforces the process described by McRobbie as 'disarticulation', by separating between middle-class mothers and working-class mothers.
\end{abstract}

\section{Keywords}

Content analysis, feminist, gender related, maternity, neoliberalism, news coverage, postfeminism

\section{Introduction}

Successful femininities increasingly have come to be defined as neoliberal identities, marking women as individualized, autonomous, freely choosing, self-monitoring and

\section{Corresponding author:}

Shani Orgad, Department of Media and Communications, The London School of Economics and Political Science, London WC2A 2AE, UK.

Email: s.s.orgad@Ise.ac.uk 
self-disciplining subjects (Gill, 2007a; McRobbie, 2009). Maternity has become one of the hallmarks of such postfeminist identity: increasingly capitalized and commodified, maternal femininity under neoliberalism has become intimately intertwined with consumer culture, embodied in the ubiquitous middle-class mother figures, such as 'yummy mummies' or 'cupcake feminists' (Bramall, 2013; Littler, 2013; McRobbie, 2013; Negra and Tasker, 2014; Tyler, 2011).

This article contributes to the growing research on the relations between mediated constructions of maternal femininities, postfeminism and neoliberalism. It focuses on the construction in the media of a specific maternal figure, namely, the 'stay-at-home' mother (SAHM), during a particular time - the global recession and its aftermath. Specifically, this article is based on a content analysis of UK national newspaper coverage of SAHMs from August 2008 to August 2013 (recession and post-recession). The combination of a focus on mothers who are outside the labour market and classified as economically 'unproductive' in the official (neoliberal) terminology and an economic crisis that potentially threatens to fracture the 'hegemonic rationality' (Couldry, 2010) of neoliberalism is used to reveal potential tensions between maternity and neoliberalism.

This article is organized into four parts. The first section considers research on mothering in economic crises and media representations of SAHMs in Europe and the United States. The second section presents the study, its methodological design, the rationale for conducting content analysis, the coding frame and hypotheses, explaining how the study's focus and design simultaneously build on and depart from extant research. The third section discusses key findings, situating them in relation to the study's hypotheses and arguments in the literature about maternity, recession and neoliberalism. The concluding section argues that the SAHM figure emerges from its press coverage as a neoliberal postfeminist subject: while it complicates the antifeminist backlash argument, it fails significantly to undermine maternal femininity's entanglement with neoliberalism.

\section{Maternity, economic crises, neoliberalism and SAHMs}

\section{Mothering and economic downturns}

Historically, in Europe and the United States, mothers have been constructed as both the cure and cause of socioeconomic crises (Gillies, 2007; Lawler, 2000), especially within periods of economic downturn (e.g. Fink and Holden's (1999) analysis of motherhood and spinsterhood in 1920s' inter-war Britain). Austerity discourses clearly interpellate a feminine subject position (Bramall, 2013), often casting women as passive and personal respondents to the economic downturn, while simultaneously stressing their responsibility and need for positive thinking (Negra and Tasker, 2014). In particular, mothers are constructed as guarantors of the social order, implying that in periods of great unrest they are accountable (Lawler, 2000: 51).

The conditions and consequences of parenting, and especially mothering, during and in the aftermath of the most recent global recession (specifically in the United Kingdom) have attracted considerable scholarly attention (Allen and Taylor, 2012; Barnes and Power, 2012; Bramall, 2013; De Benedictis, 2012; Dermott, 2012; Jensen, 2012). Jensen and Tyler (2012: n.p.) argue that in contemporary public narratives of austerity, for 
example, politics, policy, popular culture and media commentary, there is a focus on parents and construction of parenting as the reason for and solution to socioeconomic crisis in late capitalism. In the context of the framing of austerity as a necessity to cease debt and welfare restrictions on families under the UK coalition government, parents are constructed as austere, thrifty and entrepreneurial subjects, increasingly called upon to solve issues related to poverty, social inequality and civil unrest. Jensen and Tyler (2012) consider that parents are caught in a double-bind: 'being a parent makes one more vulnerable to economic austerity, whilst at the same time parents are being held more accountable than ever for the social (im)mobility of themselves and their children' (n.p.). They argue, in a Butlerian vein, that crucially 'austerity parenting' becomes a form of gendered governance, based on self-monitoring and self-governing practices. While all parents are vulnerable to this in periods of austerity, those continually created as deficient, failing and reckless by the media and political rhetoric are mothers from traditionally disenfranchised social groups. Specifically, there is a prevalent and intensified demonization of the working-class and the single mother which casts her as a pathological Other (Allen and Taylor, 2012; De Benedictis, 2012; Jensen, 2012), as opposed to 'the responsible, resilient, middle-class mother who represents "quality mothering" (McRobbie, 2012) and reflects the norms of contemporary citizenship' (Allen and Taylor, 2012: 5). In this narrative, 'good' mothers are not only able to withstand the consequences of the recession, but are able to help to reinvigorate the economy and society by governing themselves and their children in the 'right' ways. This normative view of 'good parenting' as predicated on self-governance of certain gendered selves and interlinked with the economy is intimately connected to the intensifying entanglement of mothering and neoliberalism.

\section{Maternity and neoliberalism}

'Traditional' ideologies of maternity posit mothering as independent of economic labour and incompatible with neoliberal values. However, a deep commodification of maternity under neoliberalism (Tyler, 2011), particularly in the global North, has reconfigured the 'maternal feminine' (McRobbie, 2013) from a traditionally 'asexual' and hidden state within the domestic sphere, to encompass values of consumerism, sexualization and individualization, exercised and enacted in the public sphere (Allen and Osgood, 2009; Littler, 2013; McRobbie, 2013; Tyler, 2011). McRobbie (2009) argues that a 'new sexual contract', which rests on economic and cultural activity and on consumer-based citizenship, demands women to be simultaneous labourers/consumers and mothers/carers, shifting responsibility away from the welfare state and towards individuals. It promotes a transition to a new feminine mode of activity by a series of figures such as 'the glamorous working mother, the so called yummy-mummy, the city high-flyer who is also a mother' (McRobbie, 2009: 80). Women are still generally expected to be the primary carers (Hadfield et al., 2007; Lawler, 2000; Ringrose and Walkerdine, 2008; Tyler, 2011), yet the new sexual contract, predicated on neoliberal ideology, makes their achievement of, or failure to attain, equality in relation to domestic labour and childcare a private affair.

In the current economic and political climate, against the figures of upper middleclass successful professional women on the one hand, and working-class (often single) 
mothers, who are subjected to disapproval and disapprobation on the other (De Benedictis, 2012; McRobbie, 2013), there has been an interesting and significant surfacing in the mediated public sphere of another figure: the middle-class SAHM who is outside the workforce, for instance, in the nostalgic form of the thrifty 'austerity housewife' (Bramall, 2013; Jensen, 2012) or the 'mumpreneur' (Allen and Taylor, 2012; Ekinsmyth, 2013).

\section{SAHMs: 'Yet another backlash against feminism'}

The figure of the middle-class SAHM has become a recognizable social type, although studies of its cultural representations are few. Faludi (1991) was perhaps the first to take note of the (American) media coverage of SAHMs, whom she described as the 'New Traditionalists'. Subscribing to highly stereotypical heteronormative notions of maternal femininities, depictions in popular media and American press emphasized a return to 'traditional' lifestyle values of domesticity and feminine passivity, while 'cleverly packaged in activist language, a strategy that simultaneously acknowledged women's desire for autonomy and co-opted it. The New Traditionalist [...] was an independent thinker who "made her own choices"' (Faludi, 1991: 106).

Only one study looks specifically at media representation of SAHMs, based on a content analysis of US print media (including accompanying imagery) between 1998 and 2003 of 'the professional woman who chooses family over career' (Kuperberg and Stone, 2008: 498). Kuperberg and Stone (2008) found that the portrayal of SAHMs adheres to traditional and patriarchal notions of femininity, thus legitimating and reinforcing a 'backlash'. Most news articles are associated with traditional images of heterosexual, White, middle-class and married women; the focus is 'almost exclusively on women as mothers rather than wives, and on family rather than work' (Kuperberg and Stone, 2008: 503), and childcare is the most frequently mentioned activity. Echoing Faludi's (1991) and Williams' (2000) accounts, the authors note how women's decisions to 'opt out' are framed almost exclusively through a rhetoric of choice, 'with virtually no mention of barriers, constraints, or lack of options' (Kuperberg and Stone, 2008: 506). The authors conclude that the portrayal of SAHMs signals the emergence of 'a new feminine mystique'. 'In this new mystique', they write, 'the role of mother has displaced that of wife and the decision to stay at home is distinguished from the old version by being couched in a discourse of choice' (Kuperberg and Stone, 2008: 512) and female liberation.

Recent research on the rise of 'austerity nostalgia' (Bramall, 2013) and thrift culture (Jensen, 2012; Littler, 2013; McCabe and Akass, 2006; McRobbie, 2013; Philips, 2011; Negra and Tasker, 2014) in Europe and the United States suggests that middle-class women's decisions to become full-time housewives are being romanticized and idealized as part of a nostalgic 'retreat' to patterns that characterized post-war times - especially domesticity, passive femininity and 'maternal thrift' (Negra and Tasker, 2014). Bramall (2013) argues that concurrent with historical austerity discourses, recent UK discourses legitimize women's return to the domestic setting as rational and valuable. Similarly, Akass (2012) argues that UK and US news reporting and popular media representations promote a backlash, restoring an old-fashioned familial model of male breadwinner/ dependent female carer emphasizing women as "willingly returning to their "traditional" roles in the home' (Akass, 2012: 2). Referring specifically to the British media, Akass 
(2012) observes that 'women's job losses, particularly those of mothers, is [sic] described as "positive choice" with women returning to a more "natural" state of domesticity" (p. 3 ). Those backlash narratives, she contends, legitimate and deepen inequalities and discrimination experienced by women.

McRobbie (2013) locates the contemporary trends of nostalgia, retreat and backlash specifically towards the figure of the middle-class mother/housewife, ${ }^{1}$ in the 'symbiotic relationship' (p. 124) between contemporary neoliberalism and liberal feminism. She observes how, in the unfolding of contemporary neoliberal hegemony, political and mass media discourses endorse and perpetuate the (neoliberal) commonsensical notion that

'female labour power is far too important to the post-industrial economy for anyone to be an advocate of long-term stay-at-home wives and mothers. It thus makes sense for the government to champion women who will enter the labour market and stay in it' (McRobbie, 2013: 121).

Being placed by 'choice' outside the labour market, the figure of the middle-class SAHM represents a potential challenge to, and even an attack on, the neoliberal logic, market productivity and capitalism. However, concurrently, there is increased investment in marriage, motherhood and domestic life, as a benchmark of successful femininity' (McRobbie, 2013: 130), which, rather than repudiating the SAHM, validates 'a retreat from the idea of combining full-time successful careers with motherhood' and 'gives new, more professional status to full-time mothers' (McRobbie, 2013). Within this new cultural moment, domestic skills are being professionalized, new mother-oriented markets are emerging and the SAHM (providing she is upper middle-class) is gaining renewed valued status (against her abject, the working-class single mother). She 'directs her professional skills to ensuring the unassailable middle-class status of her children' (McRobbie, 2013: 130) and manages the family as a small business, a role that provides a new rationale for 'gender re-traditionalisation' (p. 130, citing Adkins, 1999), positioning her as wife and mother, rather than worker in the labour market.

Studies highlight in the recession and post-recession UK cultural landscape a notable commercially driven nostalgic return to domesticity associated with the 'thrifty, happy and responsible housewife' (Jensen, 2012: 23). These studies are qualitative, analysing popular and consumer culture and particularly 'feminine mass media' (McRobbie, 2013: 121), for example, women's magazines (Philips, 2011), 'chick lit' and 'hen lit' novels (e.g. Littler, 2013; Thoma, 2014), 'retreat TV' (Nunn, 2011) and makeover programmes (e.g. Jensen, 2012; Philips, 2011), celebrity (Philips, 2011; Tyler, 2011) and consumerist products and practices (e.g. Bramall, 2013; Littler, 2013; McRobbie, 2013; Philips, 2011; Tyler, 2011).

\section{Content analysis of UK press coverage of SAHMs}

Building on this research, our study aims to extend the focus beyond qualitative analysis of popular culture and media, by conducting content analysis of press coverage of SAHMs in UK media coverage during recession and post-recession. It asks to what extent existing arguments about mothering and neoliberalism, and specifically SAHMs and the recession, are manifested in the current coverage of SAHMs in the UK press? Is 
the neoliberal commonsensical notion that long-term stay-at-home motherhood is undesirable due to the importance of female labour to the economy (as argued by McRobbie, 2013) advocated in this coverage? Or does the news discourse endorse SAHMs' and women's return to domesticity (as argued by e.g. Akass, 2012; Bramall, 2013)? Inspired by McRobbie's (2009) call for a 'complexification of backlash' (p. 6), the content analysis seeks to explore whether coverage of the recession provided a springboard for alternative narratives about maternity and neoliberalism, and/or challenged observations about a backlash against feminism and gender re-traditionalization.

Given the prominence of the 'hegemonic rationality' of neoliberalism (Couldry, 2010), especially during times of recession (Negra and Tasker, 2014), we expected press coverage to reflect and reinforce neoliberalism's and postfeminism's entangled embrace of market values and emphasis on economic productivity through participation in the labour force, and consequently to critique SAHMs' opting out and return to the domestic setting as attacking market productivity and capitalism. We thus hypothesized that, within UK press discussions of recession and austerity, SAHMs would be depicted predominantly as passive subjects forced out of the workforce and/or forced back into employment due to an inability to afford to remain outside of the labour market. We anticipated that the emphasis on SAHMs as passive respondents to the economic downturn (Negra and Tasker, 2014) would promote a decline in choice rhetoric and individual focus (identified in earlier depictions of SAHMs (Faludi, 1991; Kuperberg and Stone, 2008) and of postfeminist femininities more generally), in favour of a stronger focus on constraints and limits on women associated with the recession.

We conducted a content analysis of UK newspaper articles from 1 August 2008 to 1 August 2013 (recession and post-recession period) featuring the terms 'stay-at-home mothers/mums' or 'full-time mothers/mums'. Content analysis of newspaper coverage captures shifts over time, provides an in-depth insight into cultural trends (Hansen et al., 1998) and constitutes an important, but often neglected setting where ideologies and notions of gender, and maternal identities in particular, are reproduced (Van Zoonen, 1994). Furthermore, news reporting on facts relevant to the lives of women is significant since these facts are often subsumed into the field of entertainment, lifestyle and popular culture, becoming 'new forms of common sense' (McRobbie, 2009: 33, drawing on Faludi, 1991).

'Stay-at-home mother' and 'full-time mother' were chosen as the key search terms, since they are increasingly prevalent in the public lexicon, indicating a shift in the cultural terminology describing mothers who are not in paid employment (Kuperberg and Stone, 2008; McDonald et al., 2005). ${ }^{2}$ UK national newspapers and their online counterparts were searched using LexisNexis. The search included all news sections, to account for the full array of topics and discussions in which SAHMs and/or full-time mothers are mentioned. From the initial search, duplicate and irrelevant items were excluded, and a final proportional sample of 299 items was created. A coding framework was devised based on preliminary reading of the articles and informed by related academic literature and the research questions. A pilot study was carried out on 30 articles to test the framework and revise it as necessary, resulting in nine categories that comprised the final coding frame. The first four were contextual/background categories and included: Publication, Key Factor (reason for becoming a SAHM), Emphasis (whether SAHMs were the main or subfocus of the article) and Article Theme (personal, societal/ 
governmental or economy related). The remaining five categories, which are the focus of this article, aimed at unpacking in detail how the figure of the SAHM is signified and constructed, and examine what judgements and moral values are appended to her figure in the press. They include Term, Class, Framing, Orientation and Tone and are explained in detail below. The entire sample of newspaper articles was coded by one coder, and a second independent coder coded $75 \%$ of the items in the sample; intercoder reliability was $84 \%$. Questions were devised to highlight links between the different categories and the analysis was subsequently performed using SPSS. ${ }^{3}$

\section{Coding frame}

The coding frame comprises five categories. The first two, Term and Class, seek to obtain a picture of how the figure of the SAHM is characterized in the press, while the other three, namely, Framing, Orientation and Tone, focus on exploring the judgements to which this figure is subjected and the moral values attributed to her.

Term seeks to identify how the figure of the SAHM is labelled in the press coverage. It refers to the most frequently used descriptions of non-working mothers in the main text of the article. It includes 'stay-at-home mothers/mums/moms', 'full-time mothers/mums/ moms', 'housewives', 'domestic goddess/es', 'supermums' and 'other'. These terms were based on a pilot study which resulted in additional labels being added to the full sample coding. If two terms appeared equally in the article, the one in the title was used; if the title did not include one of these terms, the first occurrence in the article was used.

Class seeks to account for the strong classed character of cultural representations (and experiences) of mothering in general, and particularly in the recession (Jensen and Tyler, 2012; Negra and Tasker, 2014). Drawing on Skeggs et al. (2008), we used the subcategories of upper class/elite, upper middle-class, working-class and neither/unclear.

Framing focuses on whether stay-at-home motherhood is presented as choice or as conditioned/constrained (or neither/unclear). This category was informed by our interest in the potential tensions between emphasis on choice and coverage of recession (as explained earlier). Choice was coded if the SAHM's decision was presented as motivated and/or justified by her desire/interest in quitting a job or not entering paid employment because of motherhood. Conditioned/constrained was coded if the SAHM's decision was presented as sacrifice/enforced/determined/shaped by external factors (e.g. job loss, financial pressures).

Orientation is informed by the argument that the postfeminist sexual contract, which is based on and perpetuates neoliberal ideology, constructs women's achievements and behaviours in relation to domestic labour as private affairs (McRobbie, 2009, see discussion earlier). The category explores when and whether stay-at-home motherhood is depicted as a personal and/or private matter or as a collective, that is, if the implicit or explicit value applied to SAHMs' status/contribution/choice is portrayed as relating to and/or benefiting herself and/or her children and family, or whether SAHMs are depicted as a demographic, a social category, as subjects/citizens affected by economic or political factors or as a broader cultural figure (beyond the individual particularized story), or as mixed/neither/unclear.

Tone identifies whether SAHMs are depicted overall in a positive, favourable light, or a negative or mixed/neither/unclear. It derived from our hypothesis (based on claims 


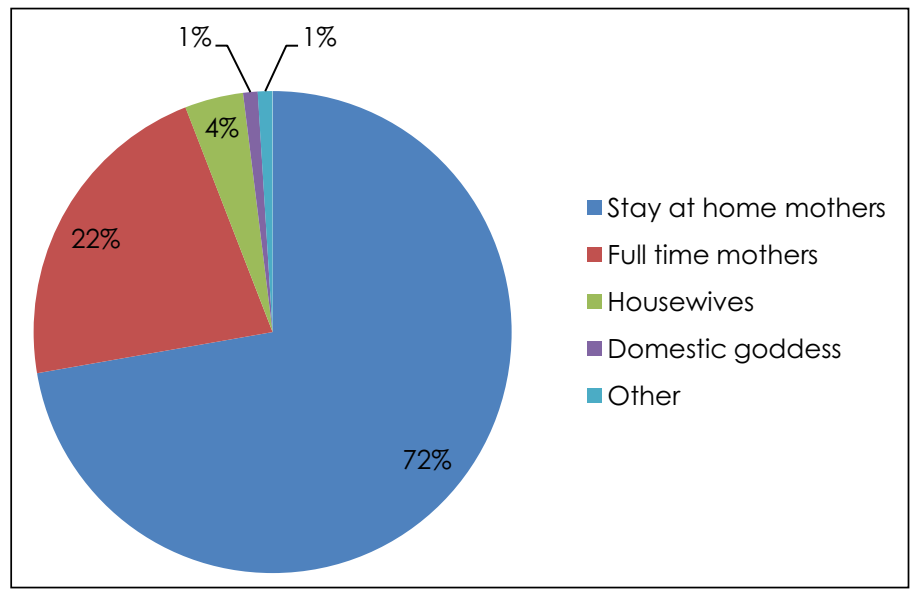

Figure I. Distribution of Term.

discussed earlier) that SAHMs will be criticized and/or depicted in a negative light because they challenge - especially in times of recession - the neoliberal emphasis on the importance of female labour power for the post-industrial economy. Articles were coded as 'positive' if they showed commendation/appraisal/valuing/appreciation/ recognition of SAHMs, and 'negative' if they demonstrated or included substantial criticism/ derision/cynicism/dismissal of SAHMs. Articles that did not fall into either of these subcategories were coded as mixed/neither/unclear.

\section{Findings and discussion}

Based on the five analytical categories discussed above that were used to code the corpus of articles, in this section, we discuss five interesting and often surprising themes: (1) characteristics of the SAHM, (2) rising visibility of SAHMs, (3) framing of stay-at-home motherhood as choice, (4) positive depiction of SAHMs and (5) concurrent depictions of stay-at-home motherhood as collective and personal.

\section{Characteristics of the SAHM}

Analysis of the newspaper coverage reveals a clear figure of a SAHM, in line with previous research (Akass, 2012; Douglas Vavrus, 2007; Kuperberg and Stone, 2008; McRobbie, 2013): she is upper class or upper middle-class, White, heterosexual and married. Of the articles, $73 \%$ used 'stay-at-home mother' as a primary term to describe non-working mothers while only $22 \%$ referred to 'full-time mother' (Figure 1). Notably, the term 'housewife' is rarely used (1\%) in newspaper coverage of SAHMs. News discourse on SAHMs is distinct from discourse on housewives, and the two are not synonymous. However, this distinction is insufficiently acknowledged or reflected in current academic accounts (see, for example, Akass (2012), Feasey (2012) and Jensen (2012) for a tendency to discuss SAHMs and housewives interchangeably). 
Table I. Cross-tabulation of Term and Class.

\begin{tabular}{llcc}
\hline & $\begin{array}{l}\text { Upper class }+ \\
\text { upper-middle }\end{array}$ & $\begin{array}{l}\text { Working } \\
\text { class }\end{array}$ & Unknown \\
\hline SAHM (73\% of total coverage) & $77 \%$ & $6 \%$ & $17 \%$ \\
$\begin{array}{l}\text { Full-time mothers (22\% of } \\
\text { total coverage) }\end{array}$ & $62 \%$ & $18 \%$ & $20 \%$ \\
\hline
\end{tabular}

Among the articles that focus on SAHMs, 77\% refer to upper middle (66\%) and upper class $(11 \%)$ women and only $6 \%$ refer to working-class women (see Table 1$)$. There is also a clear correlation between the term SAHM and the upper class and upper middleclass woman. Further qualitative observations, corroborating previous research (Douglas Vavrus, 2007; Kuperberg and Stone, 2008; McRobbie, 2013), highlighted that SAHMs are depicted as White, heterosexual and married.

Considering the impetus of the 'new sexual contract' (McRobbie, 2009), which inculcates women, especially mothers, as active socioeconomic agents in the neoliberal hegemony, the frequency of the term 'SAHM' is somewhat surprising. 'Stay at home' connotes passivity, and a subject outside of the labour force who is occupied solely with her home. In contrast, the term 'full-time mother' connotes activity and draws on employment terminology, and we therefore expected it to be more prevalent in the newspaper coverage. At the same time, the prevalence of the term 'SAHM' to describe middle-class women who are not in paid employment corroborates existing arguments about the resurgence of hearth, home and domesticity in the popular imagination of maternity (Bramall, 2013; McRobbie, 2009). Thus, the press coverage's use of the term SAHM has contradictory meanings: it appears to go against the postfeminist/neoliberal 'new sexual contract' (McRobbie, 2009) while simultaneously reinforcing austere neoliberal discourses of women harking back to domesticity.

\section{The rising visibility of SAHMs}

We note a clear rise in coverage of SAHMs over the examined period 2008-2013, with three notable peaks. The first occurs during the first quarter of 2009, the second around the middle of 2010 and the third - the sharpest of the three - from early 2011 to August 2013. This last peak is due to 93 articles on SAHMs between January and August 2013, constituting almost a third of the overall coverage along the whole period of the sample (Figure 2).

The first peak in 2009 consists of specific discussion of the value of SAHMs' domestic labour (e.g. Daily Mail (2009) and The Sun reported on a survey estimating the value of mothers' unpaid work at between $£ 32,000$ and $£ 33,000$ per year). ${ }^{4}$ It also includes reporting on SAHMs who were forced to go back to the labour market because of their families' inability to depend on former financial arrangements/income (e.g. main breadwinner's wage, state benefits). Importantly, the majority of these 2009 articles, which constitute the first peak, depict SAHMs as social and/or political subjects affected by and/or responding to radically changing financial conditions and government policies. 


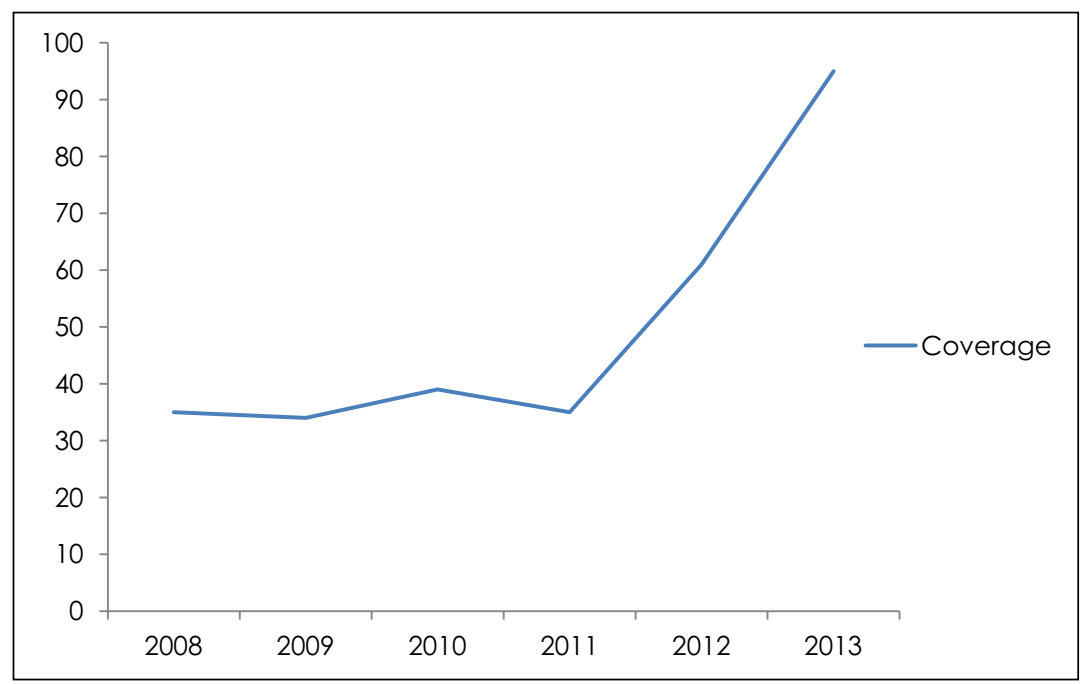

Figure 2. Coverage across time.

However, SAHMs are simultaneously depicted within a personalized rhetoric of 'choice', which works to weaken and de-politicize their identities and experiences, as we explore in the section on 'Framing stay-at-home motherhood as choice'.

From 2009, coverage of SAHMs continued to rise steadily, with a second peak in 2010. This peak is associated with more intensive discussion in the press on the impact of the recession on mothers, for example, reporting that 50,000 SAHMs had been forced to return to paid employment in 2010 (Ross, 2010), 'plunging' this demographic to the lowest level since records began and discussing child benefit cuts and proposals for potential tax breaks for married couples and SAHMs' reactions to these as 'fury'.

During the second half of 2010, coverage decreased slightly, but this changed dramatically in 2011 with a third significant rise in coverage of SAHMs. This increase is associated with extensive discussion in the press of the Coalition government's austerity-related measures, policies and cuts, many of which had direct and strong consequences for families, and women in particular (Fawcett Society, 2013). The issue of childcare costs surfaced strongly in this period, with articles such as that in the Independent on Sunday (7 August 2011) claiming that 'the UK will see a new generation of stay-at-home mothers' as 'many women are being priced out of the job market because of the soaring cost of childcare' (Merrick, 2011: 30). This, in combination with benefit cuts to families and public-sector job losses, is argued to have caused 'many mothers to choose to look after their children rather than seek paid work' (Merrick, 2011).

Overall, SAHMs' increased visibility during the 5-year study period is clearly associated with coverage of recession-related issues and the Coalition's fiscal policies. SAHMs are said to be forced out of and/or to return to the labour force, and described as directly affected by political and government policy changes and measures. This would suggest 


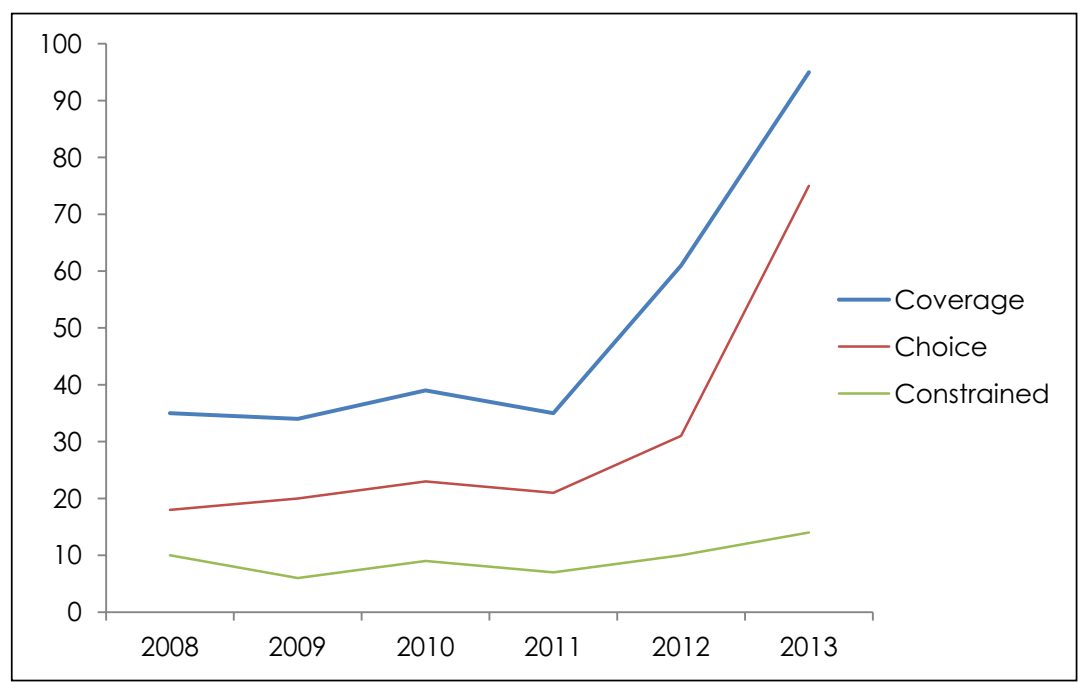

Figure 3. Coverage across time, layered with Framing.

that their depiction focuses on their identity as citizens and/or political subjects, the subjects bearing the consequences of and/or responding to the financial crisis and the government's policy changes. However, this did not happen, as explored in the next section.

\section{Framing stay-at-home motherhood as choice}

Despite the focus identified in the coverage discussed above, we found that only $18 \%$ of the entire coverage frames SAHMs as subjects conditioned and/or constrained and/or shaped by recession (e.g. job loss) or some 'larger' forces, barriers or lack of options. Rather, the majority (63\%) of the items presents stay-at-home motherhood as a choice, motivated and/or justified by the woman or women's desire or interest in wanting to quit a job or not enter paid employment. We also found a clear association between the particular peaks in coverage of SAHMs (discussed above) and an increase in the framing of stay-at-home motherhood as choice, while overall coverage of SAHM as 'conditioned' remains steadily lower (Figure 3 ).

Many of the stories discussing SAHMs in the context of recession and the impact of the government's policies frame this context as ultimately enabling and empowering rather than constraining or conditioning women to make the individualistic choice to be a SAHM. A feature in The Sunday Times magazine (10 January 2010) neatly illustrates this framing. Written by Bridget Harrison (2010), a former deputy editor of an evening newspaper, the piece weaves the personal stories of several women who held senior positions in media companies and law firms, and were made redundant following the economic recession. Harrison details her and these women's difficulties and anxieties related to becoming SAHMs following previous intense and 'adrenaline rush' jobs. 
However, gradually the narrative is redirected and the feature becomes a 'morality tale', of a blessing in disguise, in which the women have come to embrace - and even celebrate - their enforced new identity as SAHMs. 'Indeed,' Harrison writes, 'the more I witness at first-hand Joseph [her son] picking up new bits of his world, the less tedious it feels to be there when he's doing so. It's as if my brain is switching away from the rapid pace of office life, and falling into step with the mind of my son'. Hazel, another woman whose experience is reported on, 'now considers her redundancy a blessing'. She says that 'having had the decision made for me, I have to say I am delighted. If my office rang up tomorrow and said, "We've made a terrible mistake, we'd like you to come back", I really would feel sick'. The photos accompanying the piece on these new SAHMs and their children, and captions such as 'Hearth and home: Bridget Harrison is discovering the joys of being a full-time mother to her son, Joseph' (p. no. not known) firmly anchor this moral.

While previous research shows that women's decisions to leave paid employment are depicted mostly as personal empowering choice with little mention of barriers, constraints or regrets (Kuperberg and Stone, 2008; Williams, 2000), this framing appears somewhat surprising, given that in our sample SAHMs are being discussed primarily in direct relation to recession, as affected by the government's policies, often because they have been made redundant. In contrast to our expectations, SAHMs are depicted as individuals 'choosing' to become SAHMs, even when this 'choice' is forced and a direct result of the recession, for example, redundancy. Thus, the potential critique that these SAHMs could embody and voice, as subjects whose lives have been shaped by and are responding to the economic crisis and its political handling, is reduced and diffused. We return to this point in the conclusion.

\section{Positive depiction of SAHMs}

Hand in hand with the significantly larger framing of stay-at-home motherhood as choice, and its ongoing rise in the coverage during the period examined, we note an overall larger positive depiction of SAHMs. The majority (58\%) of the items demonstrate commendation and/or appraisal and/or appreciation and/or recognition of SAHMs, compared to the $31 \%$ that are critical and/or derisive and/or dismissive of SAHMs (11\% were unclear or mixed). Figure 4 shows that there is also an ongoing increase in the positive tone, with two notable sharp rises linked to the first and third coverage peaks discussed earlier.

Our findings show that the crucial and undeniable significance of female labour for the capitalist economy, which is so central to the neoliberal tenor, is not articulated in news coverage as clearly and as overwhelmingly as one might have expected. Furthermore, contra to the expectation that the government would predominantly if not exclusively 'champion women who will enter the labour market and stay in it' (McRobbie, 2013: 121), there are several examples (within the 58\% of items with a 'positive tone') of government's endorsements and appraisal of SAHMs. For example, reports of a phone-in radio programme with a SAHM, in which Nick Clegg, Deputy Prime Minister, commended this 'choice' as a 'noble' and 'admirable' choice (e.g. Cohen and Spencer, 2013; Dominiczak, 2013), and reports in which the Liberal Democrat Business Secretary 


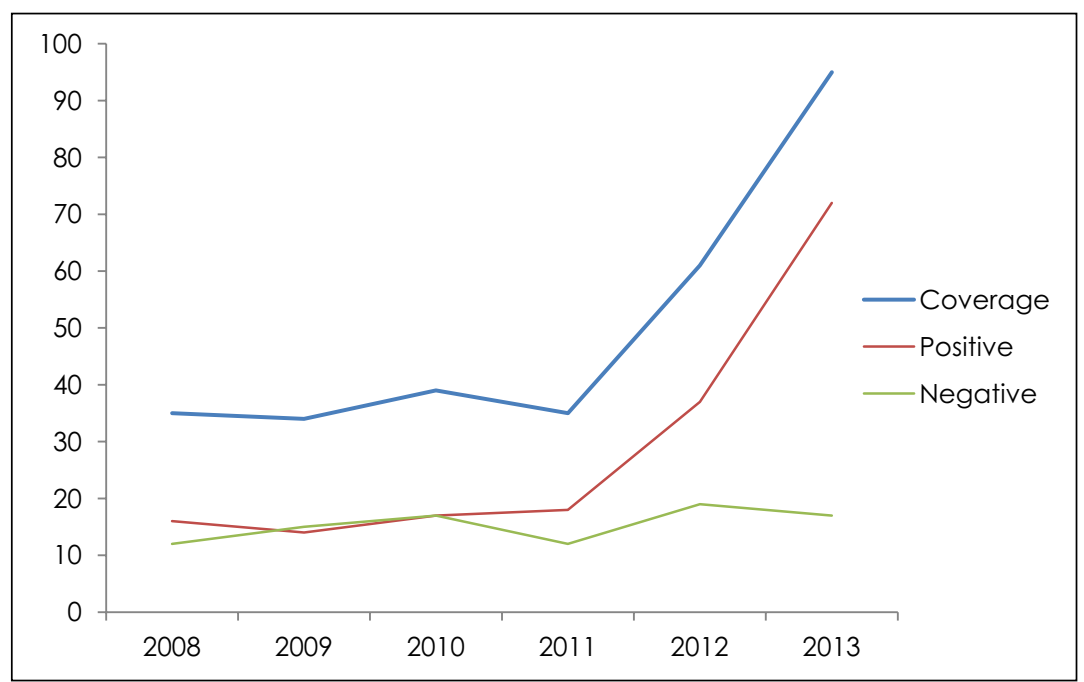

Figure 4. Coverage across time, layered with Tone.

Vince Cable dissociated himself from the Coalition's taxation 'prejudice' to SAHMs (e.g. Cohen, 2013; Ross, 2013).

Our findings confirm existing research (Allen and Taylor, 2012; De Benedictis, 2012; McRobbie, 2013) which shows that criticism and derision of mothers who are not in paid employment are predominantly directed towards working-class mothers. In our sample, among articles about working-class women, $81 \%$ took a negative tone compared with only $26 \%$ of pieces about upper class women and $26 \%$ of articles about upper middle-class women. When middle-class SAHMs are discussed negatively (which is a minority of the coverage), they are criticized mainly for their supposedly excessive, lavish, indulgent, flashy lifestyles and/or laziness associated with wealth and/or fashion, for the negative effects of being a SAHM on their well-being (e.g. isolation, boredom, frustration, lack of confidence and sense of self-worth), their perpetuation of gender inequality and their poor and/or negative intensive parenting. It can be argued that these are indirect criticisms of SAHMs being outside the labour market in a period of austerity, especially as they are frequently compared to women in employment. However, this implication is rather indirect; it is usually workingclass mothers who are directly criticized as being excessive either through fecundity, overt heterosexuality, pathological obsessing over their appearance, overly relying on and draining a crumbling welfare system, or failing to participate in the labour market, signalling their inadequate mothering (see Skeggs, 2005, for an in-depth analysis of working-class women's pathologization through excess). Thus, the positive/negative tone in the coverage of SAHMs functions as a significant divisive discursive feature, which separates and polarizes middle-class mothers, whose 'choice' to opt out of the workforce is largely endorsed and commended, and their counterparts, working-class mothers, whose similar 'choice' is criticized and derided. 


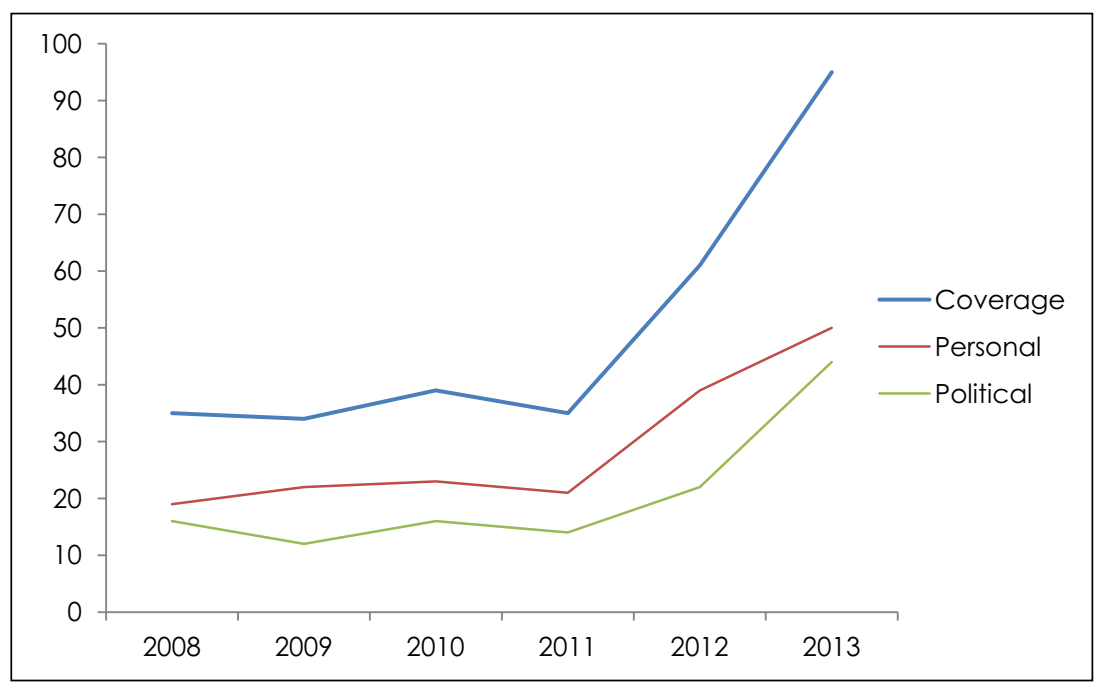

Figure 5. Coverage across time, layered with Orientation.

\section{Concurrent depiction of stay-at-home motherhood as collective and personal}

The orientation of most (59\%) of the coverage is 'personal', that is, articles treat stayat-home motherhood as a personal and/or private matter, deriving from and/or benefiting the woman as an individual, as well as sometimes also her children or family. As Figure 5 illustrates, there has been a clear rise in the personal orientation of coverage, linked to the overall rise in coverage and increased framing of stay-at-home motherhood as choice. These emphases are embedded within, and consistent with, broader postfeminist discourses of female agency, choice, individualization self-responsibilization, empowerment, freedom and female liberation (Gill, 2007b; McRobbie, 2009).

However, alongside the increased 'personal' orientation in the coverage, $41 \%$ of pieces depict SAHMs within a collective orientation, for example, as a demographic, a social or political group, or as subjects affected by economic or political forces. Contrary to expectations that the predominant framing of stay-at-home motherhood as choice would be associated almost exclusively with personal orientation (reinforcing neoliberal notions of individualization and transforming structural issues into personal matters to which private solutions must be found), we note a rise in collective orientation, albeit admittedly lower than coverage presenting stay-at-home motherhood as a personal matter. Several individual SAHMs are made visible during this period and are used by the media as 'spokespersons' articulating SAHMs' concerns and demands as political subjects. For example, former barrister turned SAHM, Laura Perrins, became a figurehead for SAHMs after a debate on a live radio call-in with Nick Clegg in March 2012. Perrins phoned in to voice her discontent with various proposed Coalition government policy changes, which she claimed discriminated against SAHMs. Perrins has subsequently become the author of a regular blog for the Wonder Women section in The Daily 
Telegraph, writing mostly about political issues affecting SAHMs, and has also become a campaigner for the group 'Mothers at Home Matter'.

This significant depiction of SAHMs as a collective suggests that news discourse introduces some recognition of women's coming-together, perhaps even solidarity, and politicizes this maternal femininity, against the de-socializing and depoliticizing of maternity and the broader 'disarticulation' of feminism (McRobbie, 2009: 26) in the contemporary cultural and political sphere. Yet to what extent does this concurrent articulation of stay-at-home motherhood as personal and political, and the coverage more broadly, offer an alternative narrative to the neoliberal 'maternal feminine' (McRobbie, 2013)? We now turn to addressing this question in the conclusion.

\section{Conclusion: The SAHM as a neoliberal postfeminist subject}

Inspired by the growing research on feminine subjectivities, neoliberal postfeminism and 'mediated maternity', this article has examined the growing visibility of the SAHM in UK news reporting during the period of recession and post-recession. Complementing current accounts that document the visibility of the SAHM in 'feminine' contexts, for example, popular media and consumerist markets, our study reveals that her figure has achieved increased luminosity in 'hard news' discourses on financial affairs and government politics.

The figure of the middle-class SAHM as it emerges from the press coverage is contradictory, and complicates the backlash argument. She is largely associated with White, middle-class, heterosexual married women, but is not the maternal figure associated with passive femininity harking back to a "'natural" state of domesticity' (Akass, 2012: 3). She is not synonymous with the 'housewife' whose resurgence has been observed as part of a consumerist-fuelled nostalgic return to domesticity in the contemporary cultural landscape (Bramall, 2013; Jensen, 2012; McRobbie, 2013). Rather, the SAHM embodies what Gill (2007b) calls 'a postfeminist sensibility': a contemporary maternal subject actively and positively choosing to be a mother, outside the labour market. She is not a productive labourer contributing directly to the neoliberal economy, yet she embodies the neoliberal/postfeminist values of choice, agency, individualization and female liberation. Surprisingly, while the neoliberal hegemonic logic would imply her derision and criticism - for she does not participate in the workforce and exercise economic activity, the SAHM emerges as a largely positive figure, whose 'choice' is valued, recognized and endorsed, including by government (as long as she is middle-class and not dependent on benefits).

How can this endorsement of women's opting out of the labour market and return to the home, which seems to be counter-commonsensical in neoliberal terms, be explained? While news discourse rarely discusses SAHMs' husbands/partners, the implicit message is that these women's 'choices' enable, and are enabled by, their husbands' economic ultra-productivity and significant contribution to the capitalist economy. Thus, the valuing and endorsement of White middle-class mothers who are 'freely choosing' to stay outside the workforce re-secure the terms of submission of White femininity and White masculine domination, perpetuating the 'postfeminist masquerade' (McRobbie, 2009: 70). Such moral judgements of SAHMs contribute to the process observed by Negra and 
Tasker (2014) in which gender inequality is being naturalized, and enduring ideological precepts about femininity, gender, class and work rebooted, in times of recession and post-recession when inequalities are ever more pronounced.

However, note that the findings complicate arguments about backlash and gender retraditionalization, showing a significant discussion in the press of SAHMs as a collective (forming $41 \%$ of the coverage). SAHMs are depicted as subjects whose identity is political insofar as it is shown to be affected and shaped by, and responds to larger structural issues, for example, economic policies, workplace inequality and so on. Thus, there is potential in the coverage for socializing and politicizing stay-at-home motherhood, influenced, perhaps, by the rise of 'mommyblogs' such as the popular UK Mumsnet, and their contribution to mothers' voices being acknowledged (importantly, by politicians) and to their representation as a community (see, e.g., Friedman, 2013). However, it is subsumed by a quantitatively heavier emphasis on the personal orientation of this identity and its framing within the rhetoric of private choice. These stronger trends obscure the larger societal, political and economic explanations of SAHMs' experiences.

Furthermore, the collective orientation of the coverage refers almost exclusively to upper and upper middle-class women, failing to include working-class women. ${ }^{5}$ In so doing, the coverage contributes to, rather than undermines, the process of disarticulation which McRobbie (2009) laments in relation to the contemporary feminine public sphere: it forces distinctions and dispenses between middle-class mothers positively described as 'SAHMs' (p. 26), and working-class mothers not in the workforce presented as a 'drain' on the state, the economy and society and described as 'chav mums', 'pramfaces' and 'benefit scroungers'. Indicative and reinforcive of postfeminism as an inherently classed and raced site of exclusion (Gill, 2007a; McRobbie, 2009), in the case of SAHMs, this works to antagonize and revitalize social hierarchies between maternal subjects and groups, rather than discussing common conditions, experiences and demands within recessionary times as a collective. Ultimately, then, the potential of the news coverage of SAHMs, especially during recession and post-recession, to reveal and fracture the fraught tensions between maternity and neoliberalism, is largely missed.

\section{Acknowledgements}

We would like to thank the anonymous reviewer and Rosalind Gill for their helpful feedback on an earlier version of this article.

\section{Funding}

This research received the support of LSE Seed Fund.

\section{Notes}

1. McRobbie (2013) does not differentiate between being in full-time work and a stay-at-home mother (SAHM); for her, both similarly represent the neoliberal maternal.

2. Searching LexisNexis from August 1960 to August 2013 indicated that (1) 'stay-at-home mother(s)/mum(s)' first appeared in April 1987 and 'full-time mother(s)/mum(s)' in October 1985; (2) their frequency has risen steadily since the 1980s, with a steeper rise in 1997-1998 and a substantially steeper rise from 2010 onwards. It is no coincidence that these terms 
emerged and gained traction in media coverage at the height of Thatcherism, New Labour and as the United Kingdom began to feel the effect of the recession and the Coalition's fiscal measures - which we explore here.

3. Some qualitative observations were also collected when coding the full sample.

4. Consistent with McRobbie (2013: 120), we found that the Daily Mail has been particularly forceful in championing the SAHM as a figure of feminine maternity.

5. Only $3 \%$ of the articles with collective orientation refer to working-class mothers.

\section{References}

Akass K (2012) Motherhood and myth-making: Despatches from the frontline of the US mommy wars. Feminist Media Studies 12(1): 137-141.

Allen K and Osgood J (2009) Young women negotiating maternal subjectivities: The significance of social class. Studies in the Maternal 1(2): 1-17.

Allen K and Taylor Y (2012) Placing parenting, locating unrest: Failed femininities, troubled mothers and riotous subjects. Studies in the Maternal 4(2): 1-25.

Barnes C and Power M (2012) Internalising discourses of parenting blame: Voices from the field. Studies in the Maternal 4(2): 1-21.

Bramall R (2013) The Cultural Politics of Austerity: Past and Present in Austere Times. Basingstoke; New York: Palgrave Macmillan.

Cohen T (2013) Cable: Stay home mums get bad deal...but we can't fix unfair tax system to help them. Daily Mail, 2 May. Available at: http://www.dailymail.co.uk/news/article-2317997/ Vince-Cable-Stay-home-mums-bad-deal-Business-Secretary-says-Government-fix-unfairtax-help-them.html. (accessed 13 May 2015).

Cohen T and Spencer B (2013) He still can't get it right! Clegg calls stay-at-home mums 'Noble'. MailOnline, 29 March. Available at: http:/www.dailymail.co.uk/news/article-2300441/ Nick-Clegg-calls-stay-home-mums-noble-Hes-condescending-say-campaigning-mothers. html. (accessed 13 May 2015).

Couldry N (2010) Why Voice Matters: Culture and Politics after Neoliberalism. London: SAGE.

Daily Mail (2009) Mothers do $£ 33,00$ unpaid work a year... 40\% more than their husbands. 16 March. Available at: http://www.dailymail.co.uk/news/article-1162217/Mothers-33-000worth-housework-year-40-husbands.html. (accessed 13th May 2015).

De Benedictis S (2012) 'Feral' parents: Austerity parenting under neoliberalism. Studies in the Maternal 4(2): 1-21.

Dermott E (2012) Poverty Vs parenting: An emergent dichotomy. Studies in the Maternal 4(2): $1-13$.

Dominiczak P (2013) We have done enough for 'Admirable' stay-at-home parents, insists Clegg. The Daily Telegraph, 29 March, p. 4.

Douglas Vavrus M (2007) Opting out moms in the news: Selling new traditionalism in the new millennium. Feminist Media Studies 7(1): 47-63.

Ekinsmyth C (2013) 'Mothers' business, work/life and the politics of 'Mumpreneurship'. Gender, Place \& Culture 21: 1-19.

Faludi S (1991) Backlash: The Undeclared War against American Women. New York: Doubleday. Fawcett Society (2013) The changing labour market: Delivering for women, delivering for growth. 24 April. Available at: http://www.fawcettsociety.org.uk/wp-content/uploads/2013/04/ Fawcett-The-changing-labour-market.pdf. (accessed 14 March 2014).

Feasey R (2012) From Happy Homemaker to Desperate Housewives: Motherhood and Popular Television. London; New York: Anthem Press. 
Fink J and Holden K (1999) Pictures from the margins of marriage: Representations of spinsters and single mothers in the mid-Victorian novel, inter-war Hollywood Melodrama and British film of the 1950s and 1960s. Gender \& History 11(2): 233-255.

Friedman M (2013) Mommyblogs and the Changing Face of Motherhood. Toronto, ON, Canada: University of Toronto Press.

Gill R (2007a) Gender and the Media. Cambridge: Polity Press.

Gill R (2007b) Postfeminist media culture: Elements of a sensibility. European Journal of Cultural Studies 10(2): 147-166.

Gillies V (2007) Marginalised Mothers: Exploring Working Class Experiences of Parenting. Oxon; New York: Taylor and Francis.

Hadfield L, Rudoe N and Sanderson-Mann J (2007) Motherhood, choice and the British media: A time to reflect. Gender \& Education 19(2): 255-263.

Hansen A, Cottle S, Negrine R, et al. (1998) Content analysis. In: Hansen A, Cottle S, Negrine R, et al. (eds) Mass Communication Research Methods. New York: New York University Press, pp. 91-129.

Harrison B (2010) Back to square mum. The Sunday Times, 10 January, pp. 18-25.

Jensen T (2012) Tough love in tough times. Studies in the Maternal 4(2): 1-26.

Jensen T and Tyler I (2012) Editorial: Austerity parenting: New economies of parent-citizenship. Studies in the Maternal 4(2). Available at: http://www.mamsie.bbk.ac.uk/back_issues/4_2/ editorial.html.

Kuperberg A and Stone P (2008) The media depiction of women who opt out. Gender \& Society 22(4): 497-517.

Lawler S (2000) Mothering the Self: Mothers, Daughters, Subjects. London; New York: Taylor \& Francis.

Littler J (2013) The rise of the 'Yummy Mummy': Popular conservatism and the neoliberal maternal in contemporary British culture. Communication, Culture \& Critique 6(2): 227-243.

McCabe J and Akass K (2006) Reading' Desperate Housewives': Beyond the White Picket Fence. London; New York: I.B. Tauris.

McDonald P, Guthrie D, Bradley L, et al. (2005) Investigating work-family policy aims and employee experiences. Employee Relations 27(5): 478-494.

McRobbie A (2009) The Aftermath of Feminism: Gender, Culture and Social Change. London; California, CA: SAGE.

McRobbie A (2013) Feminism, the family and the new 'Mediated' maternalism. New Formations 80(80): 119-137.

Merrick J (2011) Women forced out of jobs by rising cost of childcare. The Independent on Sunday, 7 August, p. 30.

Negra D and Tasker Y (eds) (2014) Gendering the Recession: Media and Culture in an Age of Austerity. Durham, NC; London: Duke University Press.

Nunn H (2011) Investing in the 'Forever Home': From property programming to 'Retreat TV'. In: Wood H and Skeggs B (eds) Reality Television and Class. London: Palgrave Macmillan, pp. 169-184.

Philips D (2011) Making do and mending - Domestic television in the age of austerity: Kirstie Allsopp's homemade homes. Paper presented at the annual IAMCR conference, Istanbul, July. Available at: http://iamcr-ocs.org/index.php/2011/2011/paper/view/2806

Ringrose J and Walkerdine V (2008) Regulating the abject: The TV make-over as site of neoliberal reinvention toward bourgeois femininity. Feminist Media Studies 8(3): 227-246.

Ross T (2010) 50,000 mothers forced back to work. The Daily Telegraph, 14 October, p. 18.

Ross T (2013) Vince cable attacks 'Prejudice' against stay at home mothers. The Daily Telegraph, 2 May, p. 1. 
Skeggs B (2005) Class, Self, Culture. London; New York. Routledge.

Skeggs B, Thumim N and Wood H (2008) Oh goodness, I am watching reality TV: How methods make class in audience research. European Journal of Cultural Studies 11(1): 5-24.

Thoma P (2014) What Julia knew: Domestic labor in the recession-era chick flick. In: Negra D and Tasker Y (eds) Gendering the Recession: Media and Culture in an Age of Austerity. Durham, NC; London: Duke University Press, pp. 107-135.

Tyler I (2011) Pregnant beauty: Maternal femininities under neoliberalism. In: Gill R and Scharff C (eds) New Femininities: Postfeminism, Neoliberalism and Subjectivity. Basingstoke; New York: Palgrave Macmillan, pp. 21-36.

Van Zoonen L (1994) Feminist Media Studies. London: SAGE.

Williams J (2000) Unbending Gender: Why Family and Work Conflict and What to Do about It. Oxford; New York: Oxford University Press. 